\title{
Intermediate Atypical Prostate Carcinoma
}

National Cancer Institute

\section{Source}

National Cancer Institute. Intermediate Atypical Prostate Carcinoma. NCI Thesaurus.

Code $C 136972$.

An agg ressive, castration-resistant, histologically distinct, metastatic carcinoma arising from the prostate gland. It is characterized by the presence of a pure population of cytologically bland malignant epithelial cells with moderate to abundant cytoplasm and rare mitotic figures. The prognosis is poor. 